\title{
Sociodemographic and Clinical Variables of Depression among Patients with Epilepsy in a Neuropsychiatric Hospital in Nigeria
}

\author{
Nasir Olamide Madandola, ${ }^{1}$ Shehu Sale ${ }^{D},{ }^{1}$ Adebayo Sunday Adebisi, ${ }^{1}$ Ayodele Obembe, ${ }^{2}$ \\ Auwal S. Salihu, ${ }^{3}$ Abdulfatai Tomori Bakare, ${ }^{2}$ and Ishak Abioda Danjuma ${ }^{1}$ \\ ${ }^{1}$ Department of Psychiatry, Federal Neuropsychiatric Hospital, Kware, Sokoto, Nigeria \\ ${ }^{2}$ Department of Psychiatry, Usmanu Danfodiyo University Teaching Hospital, Sokoto, Nigeria \\ ${ }^{3}$ Department of Psychiatry, Aminu Kano Teaching Hospital, Kano, Nigeria
}

Correspondence should be addressed to Shehu Sale; shehusale@yahoo.com

Received 29 March 2019; Revised 26 August 2019; Accepted 9 October 2019; Published 12 February 2020

Academic Editor: Janusz K. Rybakowski

Copyright (c) 2020 Nasir Olamide Madandola et al. This is an open access article distributed under the Creative Commons Attribution License, which permits unrestricted use, distribution, and reproduction in any medium, provided the original work is properly cited.

\begin{abstract}
Background. Depression is a major contributor to the global burden of disease. Its occurrence in patients living with epilepsy is not just common but also a serious comorbidity. Patients tend to suffer if the depressive disorder is undetected and thus untreated. The aim of this study is to estimate the prevalence of depressive disorder in patients with epilepsy. Also, the sociodemographic and clinical factors that are associated with the development of depression in people living with epilepsy were examined. Materials and Method. This was a descriptive cross-sectional study of participants living with epilepsy and receiving care at the Federal Neuropsychiatric Hospital, Sokoto, Nigeria. Participants were recruited consecutively as they come for follow-up care. A sociodemographic/clinical questionnaire and General Health Questionnaire version 28 (GHQ-28) were first administered to participants followed by the Composite International Diagnostic Interview (CIDI). The descriptive statistics were generated and analyzed. Logistic regression was also done to determine the predictors of depression in the study participants. All test of probability was set at $p<0.05$. Results. A total of 400 participants with epilepsy were examined with GHQ-28 and CIDI. Out of the GHQ-28 examined individuals, 71 people (17.8\%) met criteria for caseness while 35 participants $(8.8 \%)$ were depressed when assessed with CIDI. The predictors of depressive illness in participants living with epilepsy were GHQ caseness $(p \leq 0.001)$, minority ethnic group $(p=0.006)$, and a positive family history of mental illness $(p=0.021)$. Conclusion. Depression is common in people with epilepsy. Physicians should actively assess individuals with epilepsy for symptoms of depression. Special attention should be paid to patients with a family history of epilepsy and those from minority ethnic groups.
\end{abstract}

\section{Introduction}

Depression often complicates epilepsy as it is the most frequent psychiatric disorder associated with epilepsy [1]. The abnormal brain neuronal activity that causes epileptic seizures can also lead to depressive moods, and the stress of living with a chronic condition can worsen feelings of anxiety and depression [2-4]. Depressed patients are often not motivated and thus making effective management of epilepsy difficult [5]. Depression could be reactive to epi- lepsy where it is a form of negative feedback to the ongoing seizure disorder [6]. Sad feeling that is occasional is common and not strange to human beings but what separates it from a disease condition is the intensity, which is higher and for longer periods of time in depression and sometimes without any apparent reason [7-9]. Depression in epilepsy could also be before, during, or after seizure and it may not even have any relationship to the seizure.

However, depression in patients with epilepsy is underdiagnosed even among mental health professionals. 
The reasons for this include inadequate evaluation of and poor attention to the psychological states of patients with epilepsy by the treating physician. Furthermore, the management of patients with epilepsy by a large number of non-mental health professionals who do not have the expertise in eliciting these depressive symptoms portends a worse prognosis. The increasing prevalence of depression worldwide and the World Health Organization's (WHO) postulate of depression being the leading cause of death by 2020 makes this more worrisome among this subpopulation.

Evidence-based findings and knowledge of the prevalence of depression including the factors associated with its occurrence among patients with epilepsy will enhance the management of these patients by mental health professionals. This knowledge gap will also be reduced among non-mental health professionals that also treat epilepsy. It is believed that these findings will be influenced by the sociocultural background of the study setting and these are factors that will be useful to governmental/nongovernmental organizations in planning healthcare interventions and implementing policies for patients with epilepsy.

\section{Aim}

To determine sociodemographic and clinical factors associated with the occurrence of depression among patients with epilepsy in Sokoto, Northwest Nigeria.

\subsection{Objectives}

(1) To determine the prevalence of depression among patients living with epilepsy and attending the Federal Neuropsychiatric Hospital, Kware, Sokoto State, Nigeria

(2) To examine the sociodemographic and clinical factors that are associated with the occurrence of depression among patients with epilepsy in the Federal Neuropsychiatric Hospital, Kware, Sokoto State, Nigeria

\section{Methodology}

Ethical approval for this study was sought and obtained from the Ethical Committee of the Federal Neuropsychiatric Hospital, Kware, Sokoto, where the study was carried out. The sample size of 400 was derived using the sample size estimate for proportion $[10,11]$. As the outpatient departments are combined for all neuropsychiatric disorders, those with diagnosed epilepsy for at least 6 months prior to their participation were recruited consecutively after seeking their informed consent. The diagnostic criterion used to define epilepsy was the International Classification of Diseases (ICD-10) codes for epilepsy and seizures. Participants were examined with the proforma questionnaire designed by the researchers using relevant literatures. Data on their sociodemographic characteristics and clinical variables such as frequency of seizure, age at illness onset, previous substance use disorder, presence of recurrent/uncontrolled seizure, current use of antiepileptic(s), previous hospital admission on account of seizure, fear of having seizure (assessed in three domains (no fear/rarely/always)), description of family social support (assessed in three domains (reduced/no change/increased)), family history of mental illness, etc. were obtained and analyzed. Participants were initially screened with General Health Questionnaire GHQ-28 (a selfadministered questionnaire used to screen for the presence of mental illness). After administration of the GHQ-28, the participants were then administered the depression module of the Composite International Diagnostic Interview (CIDI) (a fully structured validated instrument for the assessment of psychiatric disorders). This was used to diagnose depressive disorder in the participants. It would have been difficult to reschedule these patients for another day for the administration of the CIDI. This is because quite a number of them came from afar, and they do not have access to mobile phone for ease of contact. The GHQ and CIDI were administered by one of the researchers who was trained by a CIDI certified trainer. The following inclusion criteria were observed for the study: (1) Participants were between 18 and 60 years. (2) Patients that were diagnosed with epilepsy as defined by ICD-10 codes for epilepsy and seizures. (3) All participants with clinical diagnosis of epilepsy were required to have done electroencephalography (EEG). They were recruited, whether their EEG results were positive or negative. (4) Patients that had been diagnosed and stable with epilepsy for at least 6 months.

3.1. Study Design. It was a descriptive, cross-sectional, hospital-based study.

3.2. Data Analysis. Data was analyzed using Statistical Package for Social Sciences (SPSS) version 20 software. Data were presented in tables to highlight the demographic, psychological, and clinical variables of concern, and their relationship with depression means and standard deviations (S.D) was used for descriptive statistics while the means of continuous data were compared using $t$-test. The chisquare $\left(\chi^{2}\right)$ test was used to compare categorical variables, and logistic regression was used to determine the predictors of depression. All tests of significance were set at $p<0.05$.

\section{Results}

4.1. Sociodemographic Characteristics of Participants with Depression. A total of 400 participants took part in the study of which $35(8.8 \%)$ were diagnosed as having depression. Non-Hausas were significantly more likely to be depressed when compared to Hausas. The other sociodemographic findings are as shown in Table 1.

4.2. Psychological Characteristics of Participants in Both Groups (Depressed and Nondepressed). Fear of having seizure, seizure worry, change in lifestyle, and family history of mental illness were associated with depression among the participants, see Table 2 for full details. 
TABLE 1: Comparison of the sociodemographic characteristics of the depressed and nondepressed study groups $(n=400)$.

\begin{tabular}{|c|c|c|c|c|c|}
\hline Variable & Depression group $n(\%)(N=35)$ & No depression group $n(N=365)$ & $X^{2} / t$ & D. F & $p$ value \\
\hline \multicolumn{6}{|l|}{ Age in years } \\
\hline Mean (S.D) & $30.37(8.35)$ & $28.60(9.34)$ & $t=-0.52$ & 398 & 0.60 \\
\hline \multicolumn{6}{|l|}{ Gender } \\
\hline Male & $19(7.1)$ & 247 & & & \\
\hline Female & $16(11.9)$ & 118 & $X^{2}=2.57$ & 1 & 0.08 \\
\hline \multicolumn{6}{|l|}{ Occupation by } \\
\hline Social class & $13(8.2)$ & 146 & & & \\
\hline Unemployed/social class (others) & $22(9.1)$ & 219 & $X^{2}=0.11$ & 1 & 0.86 \\
\hline \multicolumn{6}{|l|}{ Marital status } \\
\hline Married & $15(8.6)$ & 159 & & & \\
\hline Others & $20(8.8)$ & 206 & $X^{2}=0.01$ & 1 & 0.94 \\
\hline \multicolumn{6}{|l|}{ Educational status } \\
\hline Western & $10(6.6)$ & 141 & & & \\
\hline Education/NIL & $25(10.0)$ & 224 & $X^{2}=1.38$ & 1 & 0.24 \\
\hline \multicolumn{6}{|l|}{ Ethnicity } \\
\hline Hausa & $26(7.4)$ & 327 & $X^{2}=7.21$ & 1 & 0.01 \\
\hline Others & $9(10.0)$ & 38 & & & \\
\hline \multicolumn{6}{|l|}{ Religion } \\
\hline Islam & $34(8.6)$ & 360 & & & \\
\hline Christianity & $1(16.7)$ & 5 & $X^{2}=0.48$ & 1 & 0.43 \\
\hline
\end{tabular}

TABLE 2: Comparison of the psychological characteristics of the study participants in the depressed and nondepressed groups $(n=400)$.

\begin{tabular}{|c|c|c|c|c|c|}
\hline Variables & Depression group $n(\%)(N=35)$ & No depression $n(N=365)$ & $X^{2}$ & D. F & $p$ value \\
\hline \multicolumn{6}{|c|}{ Fear of having seizure } \\
\hline No & $20(57.1)$ & 290 & & & \\
\hline Yes & $15(42.9)$ & 75 & 9.12 & 1 & $<0.01$ \\
\hline \multicolumn{6}{|l|}{ Seizure worry } \\
\hline No & $10(28.6)$ & 210 & & & \\
\hline Yes & $25(71.4)$ & 155 & 10.84 & 1 & $<0.01$ \\
\hline \multicolumn{6}{|c|}{ Change in lifestyle } \\
\hline No & $6(17.1)$ & 210 & & & \\
\hline Yes & $29(82.9)$ & 155 & 20.98 & 1 & $<0.001$ \\
\hline \multicolumn{6}{|l|}{ Social support } \\
\hline Reduced & $6(17.1)$ & 42 & & & \\
\hline No change & $15(42.9)$ & 165 & 0.97 & 2 & 0.62 \\
\hline Increased & $14(40.0)$ & 158 & & & \\
\hline \multicolumn{6}{|c|}{ Family history of mental illness } \\
\hline No & $20(57.1)$ & 292 & & & \\
\hline Yes & $15(42.9)$ & 73 & 9.72 & 1 & $<0.01$ \\
\hline
\end{tabular}

4.3. Clinical Characteristics of Participants in Both Groups (Depressed and Nondepressed). Table 3 illustrates the clinical variables that were associated with depression in those with epilepsy. The presence of physical complications, lower mean duration since last seizure episode, and GHQ caseness were associated with depression.
4.4. Multivariate Logistic Regressions for the Predictors of Depression in the Study Groups. Logistic regression analysis was done for the association between the significant sociodemographic/clinical factors and depression. Only ethnicity, family history of mental illness, and GHQ caseness remained as predictors of depression, see Table 4. 
TABLE 3: Comparison of the clinical characteristics of the study subjects in the depressed and nondepressed study groups $(n=400)$.

\begin{tabular}{|c|c|c|c|c|c|}
\hline Variables & Depression group $n(\%)(N=35)$ & No depression group $n(N=365)$ & $X^{2} / t$ & D. F & $p$ value \\
\hline \multicolumn{6}{|l|}{ Seizure diagnosis } \\
\hline Grand mal & $25(8.3)$ & 277 & & & \\
\hline Others & $10(10.2)$ & 88 & $X^{2}=0.34$ & 1 & 0.56 \\
\hline \multicolumn{6}{|c|}{ Age at seizure onset (yrs) } \\
\hline $0-19$ & $22(17.6 \%)$ & 240 & & & \\
\hline $20-39$ & $13(15.8 \%)$ & 115 & & & \\
\hline $40-59$ & 0 & 10 & & & \\
\hline \multicolumn{6}{|l|}{$\geq 50$} \\
\hline \multicolumn{6}{|l|}{ Range: $1-59$} \\
\hline Mean (S.D) & $14.83(8.50)$ & $16.57(10.70)$ & $t=0.93$ & 398 & 0.35 \\
\hline \multicolumn{6}{|c|}{ Duration of seizure (yrs) } \\
\hline $0-19.9$ & $24(7.3 \%)$ & 304 & & & \\
\hline $20.0-39.9$ & $9(13.4 \%)$ & 58 & & & \\
\hline $40.0-59.9$ & $24(40 \%)$ & 3 & & & \\
\hline \multicolumn{6}{|l|}{ Range: $0.17-42.50$} \\
\hline Mean (S.D) & $15.22(11.27)$ & $11.94(8.15)$ & $t=-1.68$ & 37.48 & 0.10 \\
\hline \multicolumn{6}{|c|}{ Duration since last seizure(days) } \\
\hline $0-100$ & $30(10.5 \%)$ & 256 & & & \\
\hline$\geq 101$ & $5(4.4 \%)$ & 109 & & & \\
\hline \multicolumn{6}{|l|}{ Range: $1-5475$} \\
\hline Mean (S.D) & $69.49(155.20)$ & $223.15(573.41)$ & $t=2.41$ & 45.62 & 0.02 \\
\hline \multicolumn{6}{|c|}{ Physical complications } \\
\hline No & $20(6.3)$ & 298 & & & \\
\hline Yes & $15(18.3)$ & 67 & $X^{2}=11.76$ & 1 & $<0.01$ \\
\hline \multicolumn{6}{|c|}{ Seizure in the last one month } \\
\hline No & $12(6.2)$ & 183 & & & \\
\hline Yes & $23(11.2)$ & 182 & $X^{2}=3.21$ & 1 & 0.07 \\
\hline \multicolumn{6}{|c|}{ Psychoactive drug prior seizure } \\
\hline No & $32(8.8)$ & 333 & & & \\
\hline Yes & $3(8.6)$ & 32 & $X^{2}=0.002$ & 1 & 0.06 \\
\hline \multicolumn{6}{|c|}{ Current hard drug use } \\
\hline No & $34(9.2)$ & 337 & & & \\
\hline Yes & $1(3.4)$ & 28 & $X^{2}=1.10$ & 1 & 0.25 \\
\hline \multicolumn{6}{|l|}{ Seizure drug } \\
\hline Monodrug & $29(8.0)$ & 332 & & & \\
\hline Multiple drugs & $6(1.8)$ & 33 & $X^{2}=2.38$ & 1 & 0.13 \\
\hline \multicolumn{6}{|l|}{ Medical disorder } \\
\hline No & $30(8.3)$ & 330 & & & \\
\hline Yes & $5(12.5)$ & 35 & $X^{2}=0.783$ & 1 & 0.26 \\
\hline \multicolumn{6}{|c|}{ Previous hospitalization } \\
\hline No & $32(9.0)$ & 323 & & & \\
\hline Yes & $3(6.7)$ & 42 & $X^{2}=0.276$ & 1 & 0.43 \\
\hline \multicolumn{6}{|c|}{ Maternal pregnancy complications } \\
\hline No & $25(8.8)$ & 260 & & & \\
\hline Yes & $1(16.7)$ & 5 & $X^{2}=0.504$ & 2 & 0.78 \\
\hline Not reported & $9(8.3)$ & 100 & & & \\
\hline
\end{tabular}


TABLE 3: Continued.

\begin{tabular}{|c|c|c|c|c|c|}
\hline Variables & Depression group $n(\%)(N=35)$ & No depression group $n(N=365)$ & $X^{2} / t$ & D. F & $p$ value \\
\hline \multicolumn{6}{|c|}{ Delivery-related complications } \\
\hline No & $24(8.5)$ & 258 & & & \\
\hline Yes & $2(22.2)$ & 7 & $X^{2}=2.099$ & 2 & 0.35 \\
\hline Not reported & $9(8.8)$ & 100 & & & \\
\hline \multicolumn{6}{|l|}{ GHQ caseness } \\
\hline No & $6(1.8)$ & 323 & & & \\
\hline Yes & $29(40.8)$ & 42 & $X^{2}=111.367$ & 1 & $<0.001$ \\
\hline \multicolumn{6}{|l|}{ EEG report } \\
\hline Negative & $17(10.4)$ & 146 & & & \\
\hline Positive & $18(7.6)$ & 219 & $X^{2}=0.972$ & 1 & 0.32 \\
\hline
\end{tabular}

TABLE 4: Logistic regression analysis for the predictors of depression in the participants.

\begin{tabular}{lccccc}
\hline Predictor variable & $B$ & $p$ value & Exp(B) & Exp(B) (95\% CI) lower & Exp(B) (95\% CI) upper \\
\hline Ethnicity & -1.63 & $<\mathbf{0 . 0 1}$ & 0.20 & 0.06 & 0.64 \\
Fear of having seizure & -0.33 & 0.49 & 0.71 & 0.28 & 1.83 \\
Worry about seizure & -0.27 & 0.60 & 0.76 & 0.29 & 2.05 \\
Lifestyle change & -0.47 & 0.42 & 0.62 & 0.20 & 1.94 \\
Family history of psychiatric illness & -1.10 & $\mathbf{0 . 0 2}$ & 0.33 & 0.13 & 0.84 \\
Duration since last seizure & 0.000 & 0.83 & 0.94 & 0.77 & 1.39 \\
Seizure complication & 0.67 & 0.17 & 1.98 & 0.01 & 5.09 \\
GHQ caseness & -3.33 & $<\mathbf{0 . 0 0 1}$ & 0.04 & & 0.11 \\
Constant & 1.847 & 0.015 & 6.112 & & \\
\hline
\end{tabular}

\section{Discussion}

5.1. Sociodemographic Variables. The sociodemographic findings are similar to other studies done in some northern states of Nigeria [12]. The finding of the ethnic minorities being more likely to become depressed when compared to the major ethnic group is in keeping with an earlier study in Sokoto, Nigeria [13]. They reported that the major ethnic groups had less rate of depression when compared to the minority ethnic groups. Other studies had also buttressed this fact of ethnic minorities and depression proneness [1416]. These studies concluded that ethnic minorities lack social support among some other disadvantages. The other reasons given were that ethnic minorities experience barriers to good treatment care, they have limited knowledge, and they underutilize treatment avenues.

There was also the possibility of ethnic minorities facing lots of stress as a result of their migration which may precipitate mental illness [17].

5.2. Depression among the Patients with Epilepsy. There has been much variability in the reported rate of occurrence of depression among seizure patients by different studies. This varied from $5 \%$ to as high as $70 \%$. The $8.8 \%$ that was reported in this study is in keeping with the observations of studies that have a higher number of patients with controlled seizure (especially due to medications). They often report a preva- lence that is equivalent to the ones seen in the general population $[18,19]$.

However, a population-based, case-control study found that depression was about 3.7 times more likely to occur before initial (first) seizure than subsequently [20]. A number of reasons may explain the pathophysiology and this dualdirectional relationship between epilepsy and depression. Generally, abnormal activity of neurotransmitters especially serotonin, noradrenalin, dopamine, GABA, and glutamate and neuropathological changes in the frontotemporal regions with 5-HT1A reduction and dysfunction of the hypothalamic-pituitary-adrenal axis have been implicated in the occurrence of depression in epilepsy [21].

Depression is a leading cause of disability worldwide and is a major contributor to the overall global burden of disease [22]. This portends a poorer outcome and increased cost of treatment for epilepsy in individuals with untreated comorbid depression.

5.3. Factors Associated with Depression in the Patients with Epilepsy. Epileptic patients that were of the minority ethnic group and also those that had a family history of psychiatric illness were more likely to be depressed. The association with the ethnic minority is similar to the findings of a similar study, where increased rate of depression in ethnic minorities was found [23]. Another study which aimed among other things, to determine the demographic correlates of 
depression among patients with epilepsy reported that ethnic minority and being elderly were the predictors of having depression [24]. Individuals from a minority ethnic group may be subjected to discrimination and culture shock, especially in immigrant ethnic minorities. However, it has been reported that immigration alone does not cause serious problem but it becomes a very potent factor in mental illness when combined with other risk factors like unemployment, language difficulties, and the stress of migration [25]. All these may act as precipitants to the person that is already having a genetic loading evident by a positive family history. Majority of participants that had depression also had a family history of mental illness; this was similar to what was found in a similar study in Nigeria [26]. In another study, it was reported that a family history of depression was quite common among depressed patients with epilepsy [13]. It shows that there is an element of genetic association in those that are vulnerable to depression which may be aggravated by the epilepsy.

In a review of studies on psychiatric disorders and epilepsy, personal and/or family psychiatric history was reported to be associated with an increased risk of nonpsychiatric and psychiatric adverse effects to antiepileptic drugs (AEDs) [27]. Depression has been particularly associated with the use of barbiturates, vigabatrin, topiramate, and felbamate in patients being treated for epilepsy. The identification of patients who are more at risk of developing depression during AED therapy is therefore crucial in their management. A family history of depression is an important risk factor and should be ascertained before institution of treatment.

\section{Conclusion}

The rate of occurrence of depression in patients with epilepsy in this study is relatively high when compared to reported rates of other comorbid psychopathologies like anxiety disorders in people with seizure disorders. Mental health professionals should thus consider the regular assessment of depression in patients with epilepsy, especially those who have a family history of psychiatric disorder. This will enhance the early detection of possible comorbid depression among them. Also, patients with epilepsy of the ethnic minorities should be regularly assessed for sociodemographic factors that are negatively impacting their quality of life. Social interventions should be instituted for them when these stressors are identified.

\section{Data Availability}

The data used to support the findings of this study are available from the corresponding author upon request.

\section{Additional Points}

Limitations. The use of self-reported questionnaires could lead to bias as most of the questions were about what had happened in the past. The participants might have forgotten the actual details of events, and due to the fact that cognitive decline is a common occurrence in epilepsy, the data collected from participants are prone to recall bias. Also, the study was a cross-sectional descriptive one and thus may not be sensitive to changes in the levels of the measurements over time. This study focused on patients in the hospital setting; therefore, the findings may not be representative of what obtains in the community.

\section{Conflicts of Interest}

The authors declare that they have no conflicts of interest.

\section{References}

[1] A. M. Kanner, "Depression in epilepsy. Prevalence, clinical semiology, pathogenic mechanisms, and treatment," Biological Psychiatry, vol. 54, no. 3, pp. 388-398, 2003.

[2] S. C. Schachter, Depression and Epilepsy. Implications for AED trials. Epilepsy and Depressive Disorder, p. 33, 2010.

[3] A. Bilgiç, S. Yilmaz, S. Tiraş, G. Deda, and E. Z. Kiliç, "Depression and anxiety symptom severity in a group of children with epilepsy and related factors," Turkish Journal of Psychiatry, vol. 17, no. 3, pp. 1-8, 2006.

[4] J. M. Rey, T. T. Bella-awusah, and J. Liu, "Depression in children and adolescents," in Textbook of Child and Adolescent Mental Health, J. M. Rey, Ed., p. 32, International Association for Child and Adolescent Psychiatry and Allied Professions, Geneva, 2012.

[5] "Epilepsy, anxiety and depression," Australia, 2010http://www .beyondblue.org.au.

[6] M. Ahmad, "Epilepsy. Stigma and management," Current Research in Neuroscience, vol. 1, p. 14, 2011.

[7] A. Astill, Managing Epilepsy \& Depression, 2011, http:// beyondblue.org.au.

[8] B. S. Marco Mula, Depression in Epilepsy - Mechanisms and Therapeutic Approaches, European Neurological Disease, Nice, France, 2007.

[9] I. A. Wakawa, S. Sale, S. P. Kwajafa et al., "Depression, selfstigma and quality of life. A comparative analysis of adults on highly active antiretroviral therapy (HAART) and diabetics in a tertiary health institution in northeastern Nigeria," International Journal of Medicine and Medical Sciences, vol. 1, no. 4, pp. 50-59, 2014.

[10] G. D. Israel, Determining Sample Size, University of Florida, Gainesville, FL, USA, 1992, http://www.tarleton.edu/ academicassessment/documents/Samplesize.pdf.

[11] L. Kish, Survey sampling, Wiley, 1995.

[12] K. A. Ayanda and D. Sulyman, "The predictors of psychiatric disorders among people living with epilepsy as seen in a Nigerian Tertiary Health Institution," Nigerian Medical Journal, vol. 57, no. 1, pp. 24-30, 2016.

[13] M. A. Yunusa and A. Obembe, "Ethnic density and prevalence of psychiatric morbidity among patients with HIV infection in Sokoto, Nigeria-a control study," Open Journal of Psychiatry, vol. 2, no. 4, pp. 292-300, 2012.

[14] C. Osakwe, W. M. Otte, and C. Alo, "Epilepsy prevalence, potential causes and social beliefs in Ebonyi State and Benue State, Nigeria," Epilepsy Research, vol. 108, no. 2, pp. 316326, 2001.

[15] M. Szaflarski, J. P. Szaflarski, M. D. Privitera, D. M. Ficker, and R. D. Horner, "Racial/ethnic disparities in the treatment of 
epilepsy: what do we know? What do we need to know?," Epilepsy \& Behavior, vol. 9, no. 2, pp. 243-264, 2006.

[16] A. J. Shallcross, D. A. Becker, A. Singh et al., "Illness perceptions mediate the relationship between depression and quality of life in patients with epilepsy," Epilepsia, vol. 56, no. 11, pp. e186-e190, 2015.

[17] B. K. Puri, A. Hall, and H. O. Roger, Revision Notes in Psychiatry, Oxford University Press, London, 2nd edition, 2004.

[18] T. A. Ketter, B. A. Malow, R. Flamini, S. R. White, R. M. Post, and W. H. Theodore, "Anticonvulsant withdrawal-emergent psychopathology," Neurology, vol. 44, no. 1, pp. 55-61, 1994.

[19] M. F. O’Donoghue, D. M. Goodridge, K. Redhead, J. W. Sander, and J. S. Duncan, "Assessing the psychosocial consequences of epilepsy: a community-based study," British Journal of General Practice, vol. 49, no. 440, pp. 211-214, 1999.

[20] L. P. Bernstein, Depression, epilepsy and other psychiatric comorbidities, pp. 1-9, 2011, https://onlinelibrary.wiley.com/.

[21] D. C. Hesdorffer, W. A. Hauser, J. F. Annegers, and G. Cascino, "Major depression is a risk factor for seizures in older adults," Annals of Neurology, vol. 47, no. 2, pp. 246249, 2000.

[22] A. M. Kanner, "Depression and epilepsy: a new perspective on two closely related disorders," Epilepsy Currents, vol. 6, no. 5, pp. 141-146, 2006.

[23] "World Health Organization Bulletin," 20018, https://www .who.int/.

[24] P. Byrne, "Stigma of mental illness and ways of diminishing it," Advances in Psychiatric Treatment, vol. 6, no. 1, pp. 65-72, 2000.

[25] E. Fuller-Thomson and S. Brennenstuhl, "The association between depression and epilepsy in a nationally representative sample," Epilepsia, vol. 50, no. 5, pp. 1051-1058, 2009.

[26] D. Jayasuriya, M. McAuliffe, and M. Iqbal, "The dynamic nature of migration aspirations: findings from a longitudinal study of households in Sri Lanka," in Research Programme by Australian Government, Department of Immigration and Border Protection; Occasional Paper Series, p. 20, Department of Immigration and Border Protection,Australian Government, 2016.

[27] A. M. Kanner, "Psychiatric comorbidities in new onset epilepsy: should they be always investigated?" Seizure, vol. 49, pp. 79-82, 2017. 